\title{
A case control study on behavioural risk factors of anaemia among pregnant women delivered at a tertiary care hospital in Haryana
}

\author{
Sunny Ohlan ${ }^{1 *}$, S. K. Jha ${ }^{2}$, Parul Singhal ${ }^{1}$ \\ ${ }^{1}$ Department of Community Medicine, Shaheed Hasan Khan Mewati Government Medical College, Nuh, Haryana, India \\ ${ }^{2}$ Department of Community Medicine, BPS GMC Khanpur Kalan, Sonipat, Haryana, India
}

Received: 29 May 2021

Accepted: 30 June 2021

*Correspondence:

Dr. Sunny Ohlan,

E-mail: sunnyohlan30@gmail.com

Copyright: $\odot$ the author(s), publisher and licensee Medip Academy. This is an open-access article distributed under the terms of the Creative Commons Attribution Non-Commercial License, which permits unrestricted non-commercial use, distribution, and reproduction in any medium, provided the original work is properly cited.

\section{ABSTRACT}

Background: Anaemia in pregnancy (AIP) is one of the most common preventable causes of maternal morbidity and poor prenatal outcome. World Health Organization (WHO) has accepted up to $11 \mathrm{gm} / \mathrm{dl}$ as the normal hemoglobin (Hb) level in pregnancy. In Haryana state, the prevalence of anaemia among pregnant women is $50.2 \%$ in urban areas and $58.1 \%$ in rural areas. Pregnant women are predominantly susceptible to nutritional deficiencies because of the increased metabolic demands imposed by pregnancy and its related factors. The aim and objective of the study was to determine the behavioural factors associated with anaemia among pregnant women delivering at a tertiary care hospital in Haryana. Methods: This hospital-based case control study was carried out in BPS Government Medical College for Women, Khanpur Kalan, Sonipat (Haryana). Study was conducted for one year. One hundred sixty-eight pregnant women were enrolled for study. Inclusion criteria for cases and controls was age of 18 years and above and residents of Sonepat district. Analysis was performed by using R statistical software.

Results: The majority $57(67.9 \%)$ of cases and $49(58.3 \%)$ of controls were in age group of 18-24 years. Among different behavioral risk factors studied, not using bed nets, not wearing shoes consistently, eating pica and no use of the other drugs during pregnancy were significantly associated with anemia during pregnancy. However, on Multivariable Logistic regression analysis, the major behavioral risk factors for anemia were not using bed net during pregnancy (AOR: 1.83, 95\% CI: 0.68-5.01), and not wearing shoes consistently during pregnancy (AOR: $2.77,95 \%$ CI: 0.83-10.01). The odds of getting anaemia in pregnant mothers who reported pica during their pregnancy was AOR $=2.85$ (CI: $0.90-10.01)$ than odds of mothers who did not report pica during their pregnancy.

Conclusions: Consistent use of bed net, wearing shoes and not consuming pica prevent anaemia during pregnancy.

Keywords: Anaemia, Pregnant women, Behavioural, Case-control study

\section{INTRODUCTION}

Anaemia is defined as a decrease in the concentration of circulating Red blood cells (RBCs) or in the Haemoglobin $\mathrm{Hb}$ concentration and a concomitant impaired capacity to transport oxygen because of low level of circulating erythrocyte than the normal. ${ }^{1}$ Anaemia is a major public health problem affecting the developed as well as the developing countries in which, two thirds of them from developing countries. ${ }^{2}$ Globally, anaemia affects 1.62 billion people, which corresponds to $24.8 \%$ of the population. ${ }^{3}$ Anaemia in pregnancy (AIP) is one of the most common preventable causes of maternal morbidity and poor prenatal outcome. ${ }^{1}$ World Health Organization (WHO) has accepted up to $11 \mathrm{gm} / \mathrm{dl}$ as the normal $\mathrm{Hb}$ level in pregnancy. ${ }^{4}$

Geophagia is the ingestion of clay or soil during pregnancy. It was related to more than two-fold increase risk of anaemia. The ingestion of clay or soil impairs the absorption of iron and other nutrients, resulting in anaemia. Studies in Sudan and Kenya have shown that 
ingestion of clay was a risk factor for maternal anaemia. ${ }^{5}$ There is little research on geophagia in developing countries of eating soil on the nutritional status and parasitic infection during pregnancy is also another risk factor for development of anaemia. ${ }^{6}$

Prevention strategies to combat continued soil-transmitted helminth $(\mathrm{STH})$ transmission focus around improving sanitation sources and hygiene practices, including hand washing behaviours, proper food preparation, reduction of outdoor defecation (latrine construction etc.) and building effective sewage disposal systems. ${ }^{7}$ Reduced reliance on manure-based fertilizers and diminished barefoot activities are also important means of disrupting STH transmission. ${ }^{8}$

Bed net usage prevents malaria infection. Malaria thought to cause anaemia through a number of different mechanisms including hemolysis of parasitised red cells, immune and non-immune hemolysis of non-infected red cells, increased splenic clearance, dyserythropoeisis, and reduced red cell survival. ${ }^{9}$ In the Southern Savannah region of Mali, more than $50 \%$ of cases of anaemia in pregnant women related to malaria infection. ${ }^{10}$ High prevalence of anaemia among pregnant women persists in India despite many meticulous efforts and Anaemia Mukt Bharat Programme was launched by Government of India. Moreover, the available data concerning prevalence and specific etiologic factors of anaemia during pregnancy in Sonepat Haryana are limited. Somewhere there is a gap between government preventive and treatment measures for anaemia. The present study therefore was conducted to determine the behavioural factors associated with anaemia among pregnant women delivering at a tertiary care hospital in Haryana.

\section{METHODS}

The study was carried out in the post-natal ward of Obstetrics and Gynaecology Department, Bhagat Phool Singh Government Medical College for Women (BPSGMCW), Khanpur Kalan, Sonipat Haryana. This hospital-based case control study was conducted from March 2018 to February 2019 among pregnant women delivered at the hospital. We included delivered pregnant mothers who were more than 18 years of age, residing in Sonepat district and excluded those post-natal mothers who were not willing to participate in the study. The sample size was calculated using n Master 2.0 software by considering case to control ratio $1: 1$ and $10 \%$ non-response rate. The total number of study participants were 168 in which 84 cases and 84 controls were enrolled in the study. In sampling technique systematic random sampling was done.

Institutional Ethics Committee of our Institute approved the study. Written informed consent were taken from each study subjects. A semi-structured interview schedule was used to collect the data related to behavioral risk factors: Questions related to bed net use, latrine use, wearing shoes, pica and use of other drugs were asked. Using the
WHO definition for diagnosis of anaemia in pregnancy, the pregnant women were categorized as "Case" according to level of $\mathrm{Hb}$ less than $11 \mathrm{gm} \%$ and level of $\mathrm{Hb} 11 \mathrm{gm} \%$ or more as "Control group", based on the Hb level test result at the time of delivery as per hospital record. ${ }^{3}$ Analyses were performed by using R statistical software. Chi-square, crude odds ratio (COR), Adjusted odds ratio (AOR) with $95 \%$ Confidence Interval (CI) and $\mathrm{P}$ value were calculated. $\mathrm{P}<0.05$, was considered statistically significant.

\section{RESULTS}

The majority $57(67.9 \%)$ of cases and 49 (58.3\%) of controls were in age group of 18-24 years. The mean ages of cases and controls were 23 and 24 years with standard deviation 3.3 and 4.3 years respectively. About 26 (31\%) cases and $39(46.4 \%)$ controls used bed net while, 58 $(69 \%)$ cases and $45(53.6 \%)$ controls did not use it.

Table 1: Association of study participants according to behavioral risk factors.

\begin{tabular}{|c|c|c|c|c|}
\hline \multirow{2}{*}{ Variable } & Cases & Control & \multirow{2}{*}{$\begin{array}{l}\text { Chi- } \\
\text { square } \\
\left(\chi^{2}\right)\end{array}$} & \multirow{2}{*}{$\begin{array}{l}\mathbf{P} \\
\text { value }\end{array}$} \\
\hline & $\mathbf{N}(\%)$ & $\mathbf{N}(\%)$ & & \\
\hline \multicolumn{5}{|c|}{ Bed net usage } \\
\hline Yes & $26(31)$ & $39(46.4)$ & \multirow{2}{*}{4.24} & \multirow{2}{*}{0.038} \\
\hline No & $58(69)$ & $45(53.6)$ & & \\
\hline \multicolumn{5}{|c|}{ Defecation site } \\
\hline $\begin{array}{l}\text { Sanitary } \\
\text { latrine usage }\end{array}$ & $\begin{array}{l}83 \\
(98.8)\end{array}$ & $82(97.6)$ & \multirow{2}{*}{0.33} & \multirow{2}{*}{0.560} \\
\hline Open field & $1(1.2)$ & $2(2.4)$ & & \\
\hline \multicolumn{5}{|c|}{ Wearing shoes consistently } \\
\hline Yes & $62(73.8)$ & $74(88)$ & \multirow{2}{*}{5.55} & \multirow{2}{*}{0.018} \\
\hline No & $22(26.2)$ & $10(11.9)$ & & \\
\hline \multicolumn{5}{|l|}{ Eating Pica } \\
\hline Yes & $31(36.9)$ & $11(13.1)$ & \multirow{2}{*}{12.6} & \multirow{2}{*}{0.001} \\
\hline No & $53(63.1)$ & $73(86.9)$ & & \\
\hline \multicolumn{5}{|l|}{ Tobacco use } \\
\hline Yes & $0(0)$ & $1(1.2)$ & \multirow{2}{*}{1.006} & \multirow{2}{*}{0.316} \\
\hline No & $84(100)$ & $83(98.8)$ & & \\
\hline \multicolumn{5}{|l|}{ Other drugs } \\
\hline Yes & $1(1.2)$ & $12(14.3)$ & \multirow{2}{*}{10.08} & \multirow{2}{*}{0.001} \\
\hline No & $83(98.8)$ & $72(85.7)$ & & \\
\hline Total & $84(100)$ & $84(100)$ & & \\
\hline
\end{tabular}

Most of the participants $83(98.8 \%)$ cases and $82(97.6 \%)$ controls had used sanitary latrine while rest $1(1.2 \%)$ cases and $2(2.4 \%)$ controls went to open field for defecation. Most of the study subjects $62(73.8 \%)$ cases and $74(88 \%)$ controls were wearing shoes while rest of the $22(26.2 \%)$ cases and $10(11.9 \%)$ controls were not wearing shoes. It was found that $31(36.9 \%)$ cases and $11(13.1 \%)$ controls reported pica in which $59.5 \%$ ate multanimitti; $21.4 \%$ ate mitti; $11.9 \%$ ate chalk; $4.76 \%$ ate earthern pot and $2.3 \%$ ate lime powder while most of the respondents $53(63.1 \%)$ cases and $73(86.9 \%)$ controls did not reported pica (Table $1)$. 
Table 2: Association of study participants after Adjusting odds ratio (AOR).

\begin{tabular}{|lllllll|}
\hline $\begin{array}{l}\text { Variable } \\
\text { Bed net usage }\end{array}$ & COR & 95\% CI & P value & AOR & 95\% CI & P value \\
\hline Yes & 1 & & & & \\
\hline No & 1.93 & $(1.03-3.63)$ & 0.041 & 1.83 & $(0.68-5.01)$ & 0.22 \\
\hline Wearing shoes consistently & & & & & \\
\hline Yes & 1 & & & 1 & & \\
\hline No & 2.62 & $(1.15-5.95)$ & 0.021 & 2.77 & $(0.83-10.01)$ & 0.10 \\
\hline Eating pica & & & & & & \\
\hline No & 1 & & & & & \\
\hline Yes & 3.88 & $(1.79-8.41)$ & 0.001 & 2.85 & $(0.90-10.01)$ & 0.08 \\
\hline Other drugs & & & & & & \\
\hline Yes & 1 & & & 1 & $(2.73-57.9)$ & 0.01 \\
\hline No & 13.88 & $(1.75-111.11)$ & 0.013 & 23.7 & \\
\hline
\end{tabular}

Table 2 shows bivariable and multivariable logistic regression analyses. The Odds of getting anaemia in pregnant mothers who had not used bed net during their pregnancy was 1.83 times greater than Odds of mothers who used during their pregnancy $(\mathrm{AOR}=1.83, \mathrm{CI}$ : $0.68-$ 5.0). The Odds of getting anaemia in pregnant mothers who did not wear shoes during their pregnancy were 2.62 times higher than Odds of mothers who used to wear shoes $(\mathrm{AOR}=2.77, \mathrm{CI}: 0.83-10.01)$. The odds of getting anaemia in pregnant mothers who reported pica during their pregnancy was 2.85 times higher than Odds of mothers who did not report pica during their pregnancy $(\mathrm{AOR}=2.85$, CI: $0.90-10.01)$. The Odds of getting anaemia in pregnant mothers who had not used other drugs during their pregnancy was 23.7 times greater than Odds of mothers who used other drugs during their pregnancy $(\mathrm{AOR}=23.7$, CI: $2.73-572.9)$.

\section{DISCUSSION}

Sociodemographic characteristic of our study subjects found that majority of cases and controls were in age group of 18-24 years. The Odds of getting anaemia in pregnant mothers who had not used bed net during their pregnancy was two times higher than Odds of mothers who used bed net during their pregnancy. A study in Kenya in 2019 reported that majority of the patients diagnosed with malaria lacked treated mosquito bed nets in their homesteads and lived near dumpsites and a slow running river. ${ }^{11}$ Reason for such findings in our study may be due to that lack of awareness regarding bed net usage and another reason for not using bed nets by majority of participants may be due to use of mosquito repellent.

In our study most of the participants $98.8 \%$ cases and $97.6 \%$ controls had used sanitary latrine while rest (1.2\%) cases and $2.4 \%$ controls went to open field for defecation. A cross sectional study by Dutta et al 2013 in Bengal reported that $72 \%$ of pregnant women used sanitary latrine most of the times, $10.8 \%$ used it sometimes and $17 \%$ of the women practiced for open air defecation. ${ }^{12}$ Such findings in our study may be due to those social taboos where a father-in-law may not use the same toilet as daughter in law in the same household. In our study the Odds of getting anaemia in pregnant mothers who reported pica during their pregnancy was almost three times more than Odds of mothers who did not report pica during their pregnancy. The study by Karaoglu et al 2010 in Turkey showed that one pregnant woman out of ten was eating soil and anaemia was more prevalent among soil eaters (37.0\%). ${ }^{13}$ Soil eating (PICA) is known to be an old problem among Turkish women and it is common in many underdeveloped countries. ${ }^{14}$ Geisel et al 1998 from Kenya found that $56 \%$ of women attending antenatal clinic reported eating soil or clay regularly. Reason for such findings in our study may be due to that because of our both cases and controls were from rural population. Being a woman from the under developed rural area.

Wearing shoes was significantly high in control compared to cases $88.0 \%$ versus $73.8 \%$. in present study. A study conducted by Dutta et al 2013 in Bengal use of footwear outside the house was protecting factor for anaemia among pregnant women. ${ }^{12}$ Reason for such findings in our study may be due to that the hookworm parasite, found only in warm, moist climates where human faeces contaminated with hookworm larvae has been left in places where it might come into contact with human skin, can burrow through a bare human foot (or any part of the body that comes into contact with it) which may leads to anaemia. The present study had only $1(1.2 \%)$ case and $12(14.3 \%)$ controls used other drug during current pregnancy. Tadesse et al 2017 conducted unmatched case control study and reported that intake of drugs has a strong positive significant association with the occurrence of anaemia among pregnant women. ${ }^{15}$ Another study conducted by Dainiak et al, 1988 found that drugs were supposed to cause anaemia either by interfering with the absorption of micronutrients or inhibiting the effect of erythropoietin that is important for $\mathrm{Hb}$ production. ${ }^{16}$ Reason for such findings in our study may be because of that extra care regarding their health. Another reason maybe that they were using Protein $-\mathrm{X}$ (Heme Protein), B- 
complex capsules or steroids in some form which may lead to increase RBCs growth.

\section{CONCLUSION}

The present study concluded that consistent use of bed net, wearing shoes and not consuming pica prevent anaemia during pregnancy.

\section{Recommendations}

We recommend further community-based studies to identify other risk factors of anaemia associated with pregnant women with large sample size and more study design. Since Pregnancy is the most nutritionally demanding period in woman's life, pregnant women should be encouraged and educated to eat more diversified food not pica and encourage wearing shoes. More strengthening of Anaemia tracking System (ATM), so that all dropouts cases to be reported \& traced and timely intervention or treatment should be given to the needy. It is also recommended that health promotion and behavioural promotion campaigns on anaemia be organized at places of contact with pregnant women and women of reproductive age group i.e. Pregnant Women Club are made where they shares their experiences of pregnancy and help out the future pregnancies.

\section{Funding: No funding sources}

Conflict of interest: None declared

Ethical approval: The study was approved by the Institutional Ethics Committee

\section{REFERENCES}

1. World Health Organization. Micronutrient Deficiencies: Prevention and Control Guidelines. World Health Organization. 2015. https://www.who.int/docs/defaultsource/nutritionlib rary/preventing-and-controllingmicronutrient-defici encies-in-populations-affected-byan-emergency.pdf ?sfvrsn=e17f6dff_2. Accessed on $20^{\text {th }}$ April, 2021.

2. Goonewardene M, Shehata M, Hamad A. Anaemia in pregnancy. Best Pract Res Clin Obstet Gynaecol. 2012;26(1):3-24.

3. De Benoist B, Cogswell M, Egli I, McLean E. Worldwide prevalence of anaemia 1993-2005; WHO Global Database of anaemia. 2008. https:// www.who.int/nutrition/publications/micronutrients/PH Nmay2008.pdf. Accessed on $20^{\text {th }}$ April, 2021.

4. World Health Organization. The world health report 2002: reducing risks, promoting healthy life. World Health Organization. 2002. https://apps.who.int/ iris/handle/10665/67454. Accessed on $20^{\text {th }}$ April, 2021.
5. Adam I, Khamis AH, Elbashir MI. Prevalence and risk factors for anaemia in pregnant women of eastern Sudan. Transactions of the Royal Society of Tropical Medicine and Hygiene. 2005;99(10):739-43.

6. Karaoglu L, Pehlivan E, Egri M, Deprem C, Gunes G, Genc MF et al. The prevalence of nutritional anaemia in pregnancy in an east Anatolian province, Turkey. BMC Public Health. 2010;10(1):329.

7. Bethony J, Brooker S, Albonico M, Geiger SM, Loukas A, Diemert D et al. Soil-transmitted helminth infections: ascariasis, trichuriasis, and hookworm. The lancet. 2006;367(9521):1521-32.

8. World Health Organization. Soil-transmitted helminth infections Fact Sheet. 2018. Available from: http://www.who.int/mediacentre/factsheets/fs366/en. Accessed on 20th April, 2021.

9. Matteelli A, Donato F, Shein AJ, Muchi JA, Leopardi O, Astori L et al. Malaria and anaemia in pregnant women in urban Zanzibar, Tanzania. Annals of Tropical Medicine \& Parasitology. 1994;88(5):475-83.

10. Bouvier P, Doumbo O, Breslow N, Robert CF, Mauris A, Picquet $\mathrm{M}$ et al. Seasonality, malaria, and impact of prophylaxis in a West African village I. Effect on anaemia in pregnancy. The American journal of tropical medicine and hygiene. 1997;56(4):378-83.

11. Ndegwa SK. Anaemia \& its associated factors among pregnant women attending antenatal clinic at $\mathrm{M}$ bagathi County Hospital, Nairobi County, Kenya. African Journal of Health Sciences. 2019; 32(1):59-73.

12. Dutta S, Chatterjee S, Sinha D, Pal B, Basu M, Dasgupta A. Correlates of Anaemia and Worm Infestation among Rural Pregnant Women: A Cross Sectional Study from Bengal. Natl J Community Med. 2013;4(4):603-07.

13. Karaoglu L, Pehlivan E, Egri M, Deprem C, Gunes G, Genc MF et al. The prevalence of nutritional anaemia in pregnancy in an east Anatolian province, Turkey. BMC Public Health. 2010;10(1):329.

14. Okcuoglu A, Arcasoy A, Minnich V, Tarcon Y, Cin S, Yorukoglu OR et al. Pica in Turkey. The incidence and association with anaemia. The American journal of clinical nutrition. 1966;19(2):125-31.

15. Tadesse SE, Seid O, G Mariam Y, Fekadu A, Wasihun Y, Endris K, et al. Determinants of anaemia among pregnant mothers attending antenatal care in Dessie town health facilities, northern central Ethiopia, unmatched case -control study. PLoS ONE. 2017;12(3):e0173173.

16. Dainiak N, Worthington M, Riordan MA, Kreczko S, Goldman L. 3'-Azido-3'-deoxythymidine (AZT) inhibits proliferation in vitro of human haematopoietic progenitor cells. British journal of haematology. 1988;69(3):299-304.

Cite this article as: Ohlan S, Jha SK, Singhal P. A case control study on behavioral risk factors of anaemia among pregnant women delivered at a tertiary care hospital in Haryana. Int J Reprod Contracept Obstet Gynecol 2021;10:3062-5. 